absence of any obvious intrinsic rewards. In the case of the two-part puzzles. these Ss showed lower final asymptotic performance than did controls. indicating the apparent loss of interest in the testing device. In contrast, the malnourished Ss showed only a slight, but not significant, reduction in performance when compared with normals in the three-part puzzles. There is no way to determine from this data if the differences between the results of these two experiments were due to the complexity of the task, early effects of the diet. or repeated testing.

The major change appears to be the decrease in performance of the high-protein $S s$ in the three-part puzzle. The low-protein Ss continued to respond at a frequency that was consistent with their performance on the first puzzle. The high-protein Ss may have shown increased satiation to the situation, or the low-protein Ss may have had abnormally low scores on the first test due to some other variable. It is likely that the latter situation was the case. During the testing of the first experiment, most of the malnourished Ss showed signs of infective diarrhea, a disease that typically accompanies the PCM syndrome. By the time the Ss were on the diet for over 200 days, the diarrhea symptoms had disappeared and these malnourished monkeys were beginning to show a modest weight gain. Thus, they may have been adapted to the diet at the time they were exposed to the three-unit puzzle.

This interpretation is supported by other observations at our laboratory that indicate that early in the diet. low-protein Ss also showed loss in learning set and object discrimination that was associated with secondary infection.

It is clear that in animal research, as well as in human studies of PCM, the possible influence of 'satellite' diseases and systemic malfunctions associated with the protein deficiency must be taken into account. These secondary factors may be responsible for, or contribute to, the observation of reduced manipulatory responsiveness in malnourished children.

\section{REFERENCES}

HARLOW, H. F. Learning and satiation of response in intrinsically motivated complex puzzle performance by monkeys. Journal of Comparative \& Physiological Psychology 1950, 43. 289-294.

HARLOW, H. F., HARLOW, M. K. \& MEYER, D. R. Learning motivated bv a manipulation drive. Journal of Experimental Psychology, 1950, to 228-234.

HARLOW, H. R., BLAZEK, N. C. \& MCCLEARN. G. E. Manipulatory motivation in the infant rhesus monkey.
Journal of Comparative \& Physiological Psychology 1956, 49, 444.448.

JELLIFFE D, B. \& WELBOURN, H. F Clinical signs of mild-moderate protein-calorie malnutrition of early childhood. In G. Blix (Ed.). Mild-moderate forms of protein-calorie malnutrition. Uppsala: Almqvist Wiksells, 1963.
TROWELL. H C.. DAVIES. J. Y. P.. \& DEAN, R. F. A. Kuashiorlior. London: Arnold, 1954

ZIMMERMANN. R, R.. \& STROBEL. D. A. Effects of protein malnutrition on visual curiosity manipulation. and social behavior in the infant thesus monkey. Proceedings. 77 th Annual Convention. APA. $1969,241.242$.

\title{
CRF pretraining and differential magnitude discrimination*
}

\author{
KENNETH L. TRAUPMANN and PAUL T. P. WONG \\ University of Texas at Austin, Austin, Tex. 78712
}

Rats were given CRF pretraining in a black alley, which became either the positive or the negative stimulus in a subsequent discrimination based on differential magnitudes of reward. Discrimination developed more rapidly when the black alley became the negative stimulus.

Amsel \& Ward (1965) have presented a series of experiments concerning the effects of prediscrimination treatments on vigor discriminations where continuous reinforcement was associated with a runway of one brightness $(\mathrm{S}+)$ and nonreward was associated with a runway of another brightness (S-). Discrimination developed faster when Ss had CRF prediscrimination training to $\mathrm{S}-$ than when pretraining was to $\mathrm{S}+$. That is, if CRF training was given in, say, a black alley $\left(S_{B}\right)$, discrimination developed more rapidly when $S_{B}$ became $S-$ and a novel white alley was $S+$ than when the reverse was

- This research was supported by NSF Grant GR-14990X awarded to Abram Amsel. whose assistance is gratefully acknowledged. We would like to thank Laura Andrews for aiding in the collection of the data. true, i.e., $S_{B}+S_{W}-$. The present experiment was an attempt to extend these findings to the case where $S$ was some smaller reward than $S^{+}$, i.e., the case where discrimination is based on differential magnitudes of reward.

\section{METHOD}

The Ss, which were approximately 90 days old on arrival in the laboratory, were 14 male albino rats obtained from Holtzman Farms, Madison, Wisconsin. They were fed Wayne lab chow ad lib for 1 week after arrival and then were fed $14 \mathrm{~g}$ of chow each day for 2 weeks, after which the experiment was begun. The feeding regimen was continued throughout the experiment. During the period of deprivation, the Ss were occasionally handled by being removed from their home cages, gently jostled, and returned.

The apparatus was two $3 \cdot \mathrm{ft}$ 


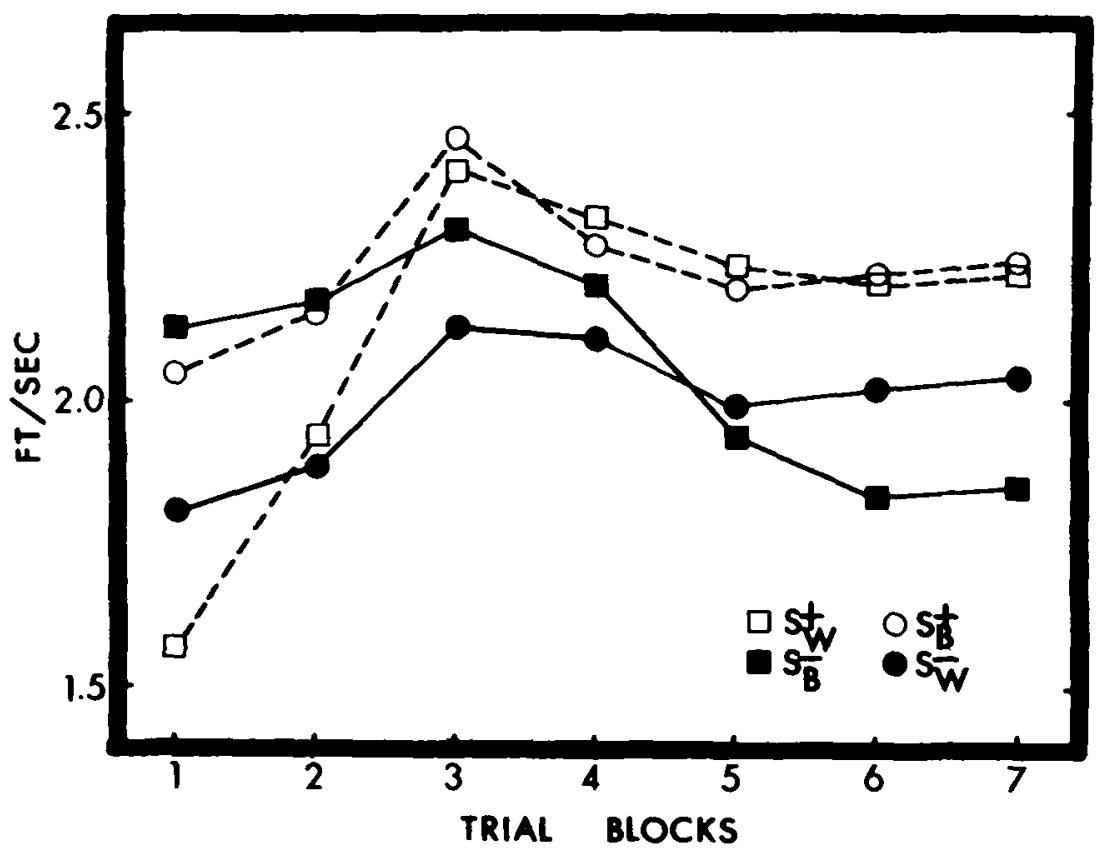

Fig. 1. Discrimination performance to $S+$ and $S-$ for Groups $S_{B}+S_{W}-$ and $\mathbf{S}_{\mathbf{W}}+\mathbf{S}_{\mathbf{B}}$.

alleyways, 3 in. wide and 4 in. high, covered with clear Plexiglas. The alleys were situated on runners so that each could be positioned in front of a 12-in. gray startbox. Connnected to the startbox through a guillotine door was a 12-in. entrybox. The startbox door was of clear Plexiglas, and the goal doors, located 12 in. from the goal end of the alleys, were painted the same color as their respective alleys, i.e., flat black or flat white. U-shaped goalcups were positioned on the end wall, 1.5 in. from the floor. Photocells were located 1,2 , and $3 \mathrm{ft}$ from the start door, which, in conjunction with activation of the start door, provided three measures of running time.

All Ss were first given $40 \mathrm{CRF}$ running trials in the black alley for a 300-mg reward. Training was given at four trials per day with an intertrial interval of approximately $12-15 \mathrm{~min}$. The Ss were allowed to remain in the goalbox until they finished eating the reward pellet. Approximately $1 / 2 \mathrm{~h}$ after each day's session, Ss were fed their ration.

Discrimination training was subsequently conducted whereby, for a random half of the $S s$, a $500-\mathrm{mg}$ pellet was obtained in the black alley $\left(S_{B}{ }^{+}\right)$and a 97-mg pellet was obtained in the white alley $\left(S_{W}-\right)$. For the other half of the Ss, the situation was reversed, i.e., $S_{W}+$ and $S_{B}-$. Training was continued at four trials per day for 14 days. The reward sequences were such as to equate for $\mathrm{S}+\mathrm{S}+$, $\mathbf{S}+\mathbf{S}-, \mathbf{S}-\mathbf{S}+$, and $\mathrm{S}-\mathrm{S}-$ transitions, while providing two $S+$ and two $S^{-}$ trials each day.

RESULTS AND DISCUSSION

Analyses of variance were conducted over the speed data (1/time) from all alley segments. For brevity, only the start data are presented (Fig. 1), since here the discrimination was most obvious. The run and goal data showed similar trends, nevertheless.

Analysis of the start speeds in blocks of four trials showed a Reward by Stimulus by Block interaction, $F(6,570)=8.42, \quad p<.01$. This interaction resulted from initially faster running in $S_{B}$, irrespective of reward magnitude, $F(1,570)=5.34$, $\mathrm{p}<.05$, combined with a crossover in responding to $S+$ and $S-$ for the $\mathrm{S}_{\mathrm{W}}+\mathrm{S}_{\mathrm{B}}-$ group, $\mathrm{F}(6,570)=3.70$, $\mathrm{p}<.01$. For this group, running was reliably faster to $S_{W}+$ than to $S_{B}-$ on both Trial Blocks 6 and 7 , $\operatorname{Fs}(1,570)=4.43$ and 4.27 , ps $<.05$, clearly demonstrating the development of a discrimination. For the $S_{B}+S_{W}$ group, on the other hand, there was no reliable differential responding to $\mathrm{S}+$ and $s-$ over Trial Blocks 5,6 , or 7 , either taken singly or in combination (all Fs $<1.0$ ). The apparent slower running to $S_{W}$ - by this group may be attributed to the performance of one $S$, which tended to avoid $S_{W}$ from the beginning of discrimination training while always running rapidly in $S_{B}$.

The evidence presented here is straightforward in replicating and extending the Amsel \& Ward (1965) findings. Likewise, it is deducible from frustration theory (Amsel, 1967).
Since $S_{B}$ had been associated with large reward during pretraining, the shift from large to small reward in $S_{B}$ for Group $S_{W}+S_{B}-$ should have resulted in the development of anticipatory frustration $\left(r_{F}\right)$, which is assumed to be the mechanism for the negative contrast effect. Group $S_{B}+S_{W}-$ should also experience $r_{F}$ during discrimination, but to a lesser degree, since $\mathbf{S}$ - for this group is $S_{W}$ and anticipatory reward $\left(r_{R}\right)$ resulting from large-reward training is experienced in $\mathbf{S}_{\mathbf{W}}$ only insofar as there is primary stimulus generalization from $S_{B}$ to $S_{W}$. Thus, these data support the notion of primary stimulus control over the development of $\mathrm{r}_{\mathrm{F}}$.

The present finding is also consistent with previous evidence (Mackinnon, 1965) that vigor discriminations based on differential reward magnitude develop more rapidly and to a greater extent in the start measure than the run or goal measures of the typical runway situation. Amsel (1967) has pointed out that this phenomenon is probably due to the fact that the $\mathbf{S}$ sees the stimulus associated with large or small reward as soon as he enters the alley and, therefore, has all the information necessary to know whether it is an S+ or S- trial. The phenomenon does not seem to be explainable by the frustration hypothesis, however, since both $r_{F}$ and $r_{R}$ gradients are postulated to increase with goal proximity and the $r_{F}$ gradient is taken to be both lower and of steeper slope than the $r_{R}$ gradient. These relationships provide for greater differences in performance between $\mathrm{S}+$ and $S-$ with goal proximity, independent of the reward magnitudes associated with $\mathbf{S}+$ and $\mathbf{S}-$. Hence, this phenomenon appears anomalous to frustration theory; however, we know of no other position that purports to account for it.

\section{REFERENCES}

AMSEL, A. Partial reinforcement effects on vigor and persistence. In $K$. W. Spence and J. T. Spence (Eds.). The prychology of learning and motivation. New York: Academic Press, 1967.

AMSEL, A., \& WARD, J. S. Frustration and persistence: Resistance to discrimination following prior experience with the discriminanda. Psychological Monographs, 1965,79(4, Whole No. 597).

MackINNON, J. R. Acquisiton and extinction performance to one discriminandum as a function of reward value associated with the other. Doctoral thesis, University of Toronto, 1965 . 